\title{
Consumidores Satisfeitos, e Então? Analisando a Satisfação como Antecedente da Lealdade
}

\author{
Juliano Aita Larán \\ Francine da Silveira Espinoza
}

\section{Resumo}

Em busca de maiores esclarecimentos com respeito à formação da lealdade conativa em função da satisfação, foi realizado um experimento de campo para avaliar a relação entre estes dois construtos. O trabalho apresenta base teórica, sustentando o relacionamento proposto, bem como um método de pesquisa que permitiu que a avaliação da satisfação do consumidor fosse processada e mensurada logo após o consumo efetivo do produto, propiciando um julgamento mais preciso e melhor mensuração das variáveis. Os resultados obtidos indicam uma relação positiva entre as duas variáveis e que uma parte considerável da variância da lealdade é explicada pela satisfação, contribuindo para o avanço da investigação dos desdobramentos da satisfação e, principalmente, da formação da lealdade.

Palavras-chaves: comportamento do consumidor; satisfação; lealdade.

\begin{abstract}
In search of deepening the knowledge on the relationship between consumer satisfaction and loyalty, we conducted a field experiment. The article presents the theoretical basis supporting the proposed relationship, as well as a research method in which consumer's satisfaction judgment was processed right after the consumption of the product, proportioning a more precise judgment and better variables measurement. Results indicate a positive relationship between the two variables and a considerable amount of loyalty's variance is explained by satisfaction, contributing to advancing investigations on the consequences of satisfaction and loyalty formation.
\end{abstract}

Key words: consumer behavior; satisfaction; loyalty. 


\section{INTRODUÇÃO}

Com contribuição considerável para o avanço da teoria na área de comportamento do consumidor, o tema satisfação do consumidor já foi amplamente abordado na literatura internacional e nacional e trouxe consigo uma gama de outros tópicos relacionados ao assunto. Dentre os assuntos mais estudados, encontram-se os antecedentes da satisfação e as teorias que procuram explicar a formação deste sentimento, por meio de fatores cognitivos e emocionais. Por outro lado, as conseqüências da satisfação não obtiveram o mesmo grau de destaque e são consideradas igualmente importantes, sobretudo para a abordagem gerencial de comportamento do consumidor, que visa a uma aplicação mais direta das teorias desenvolvidas. É como conseqüência da satisfação que a lealdade do consumidor será abordada neste trabalho.

O processo pelo qual o consumidor se decide por repetir a compra e/ou tornarse leal a um produto, marca ou loja foi pouco elucidado pela literatura de marketing (Oliver, 1999) e ainda hoje permanece em tal situação (Lemon et al., 2002; Sindershmukh et al., 2002), carecendo até mesmo de escalas que mensurem e diferenciem as diversas facetas da lealdade (Ellis, 2000). Dentre as motivações que levam os consumidores ao comportamento leal destaca-se o papel dos julgamentos em relação à experiência de consumo, pois essas avaliações ou julgamentos são fatores de alta influência na formação de atitudes e intenções de ação.

Inserido neste contexto, o objetivo deste trabalho é explorar a formação da lealdade conativa (intenção de ação), conforme definida por Oliver (1999), a partir da avaliação de uma experiência de consumo, sendo incitada pelo sentimento de satisfação. Primeiramente, são revisados os principais conceitos de satisfação e lealdade abordados na literatura, bem como se busca sustentar teoricamente o relacionamento dos dois construtos. A seguir, o modelo estrutural apontado a partir desta relação foi testado com base em dados colhidos em experimento de campo, em que as respostas às questões propostas foram medidas após a degustação de um produto alimentício. Com os resultados obtidos no experimento espera-se contribuir na busca do entendimento da formação da lealdade a partir da satisfação. 


\section{Satisfação do Consumidor}

O construto satisfação tem gerado teorias que oferecem tanto contribuições acadêmicas quanto aplicações na prática de marketing. Apesar do sobressalto que envolveu o assunto desde o início da década de oitenta até os dias atuais, o construto parece não dispor de conceituação definitiva.

Oliver (1997, p.13) define satisfação como a "resposta ao contentamento do consumidor, o julgamento de que uma característica do produto ou serviço, ou o produto ou serviço em si, ofereceu (ou está oferecendo) um nível prazeroso de contentamento relativo ao consumo, incluindo níveis maiores ou menores de contentamento". De maneira geral, satisfação é o julgamento formado durante o uso ou consumo de produto ou serviço de determinado fornecedor, ou depois dele; portanto constitui uma reação ou sentimento em relação a uma expectativa (Solomon, 1999). Essas definições ressaltam tanto aspectos cognitivos quanto emocionais da satisfação, que se constitui num sentimento que surge como resultado da avaliação subjetiva de que a alternativa escolhida atende ou excede as expectativas (Bloemer e Kasper, 1995). Em resumo, a satisfação é estado psicológico resultante do processo de compra e de consumo (Evrard, 1993).

A desconfirmação de expectativas é amplamente apresentada como determinante da satisfação dos consumidores (Oliver, 1980; Churchill e Surprenant, 1982 entre outros). Segundo esse paradigma, o consumidor forma expectativas anteriores ao consumo, observa o desempenho do produto e compara o desempenho percebida com as expectativas iniciais. As expectativas são pensamentos que criam um padrão de referência para o julgamento do consumidor; quando os resultados são diferentes deste padrão, ocorre a desconfirmação. Se o resultado for melhor do que esperado, a desconfirmação será positiva; se for pior do que o esperado, há desconfirmação negativa, tendendo a gerar insatisfação.

O desenvolvimento da teoria levou à incorporação de emoções (reações afetivas) nos modelos de satisfação. Com isso percebeu-se aumento na capacidade prognóstica dos modelos. O estado afetivo do consumidor referese aos sentimentos positivos e negativos que os consumidores associam com o produto ou serviço após a compra e durante o uso (Mowen e Minor, 1998). As emoções positivas e negativas estão relacionadas à satisfação e à insatisfação, respectivamente. A combinação da desconfirmação das expectativas e das emoções predizem melhor a satisfação do que apenas a avaliação do desempenho. 


\section{Conseqüências da Satisfação}

Ainda que a academia tenha centrado seus esforços no desenvolvimento de modelos explanatórios do processo de formação da satisfação, é possível encontrar na literatura alguns estudos que propõem e, muitas vezes, testam empiricamente algumas conseqüências e comportamentos que são gerados a partir deste julgamento.

Alguns benefícios gerenciais podem ser retirados do trabalho de Fornell (1992), que indicou menor elasticidade de preço, menores custos nas transações futuras, custos menores para atrair novos clientes e a melhora na reputação da empresa como resultantes do alto grau de satisfação dos clientes. Em termos comportamentais, a satisfação, obtida a partir de consecutivas experiências bem sucedidas, é importante fator para predizer as intenções futuras de ação dos consumidores. Relações entre satisfação e intenções de comportamento podem ser encontradas nos trabalhos de Anderson et al. (1994), Zeithaml et al. (1996), Cronin e Taylor (1992), Garbarino e Johnson (1999).

Entretanto algumas variações nesta relação devem ser consideradas. De acordo como os resultados de Garbarino e Johnson (1999), a satisfação direciona as intenções futuras dos clientes caracterizados como transacionais, quando então a satisfação também é um dos fatores que determinam a confiança e o comprometimento do cliente. Tais resultados são corroborados por Bolton (1998), que afirma que a satisfação tem papel fundamental nos estágios iniciais do relacionamento: se as experiências do cliente não forem satisfatórias nos primeiros encontros, eles tenderão a permanecer menos tempo com a empresa. Geralmente, clientes que estão satisfeitos têm menor tendência a terminar o relacionamento (Jap, 2001). Dessa forma, entender as intenções futuras dos clientes é de suma importância para estimar o seu potencial de continuar com a organização ou deixá-la (Zeithaml et al., 1996).

O estudo das conseqüências apontadas acima é interessante e pertinente. No entanto outra conseqüência da satisfação, que se manifesta com relativa freqüência em termos conceituais e empíricos, é a lealdade. Sob a ótica do consumidor, pode-se entender que ele tenderá a ser fiel, quando se sentir satisfeito, já que a satisfação influenciará a sua atitude em relação ao objeto em exame (Oliver, 1997). Antes de abordar esta relação com profundidade, em busca de sustentação teórica, será feita uma revisão dos conceitos de lealdade e do processo psicológico que leva à formação de atitude e intenção de comportamento. 


\section{LEALDADE}

O comportamento definido como lealdade representa não apenas significado comportamental, caracterizado pela repetição da compra, mas também significado psicológico (Jacoby e Chestnut apud Oliver, 1999). De acordo com essa visão, não é correto fazer qualquer inferência sobre lealdade apenas com base em padrões de compra repetida, uma vez que a lealdade verdadeira inclui, além do comportamento, uma resposta atitudinal, constituída por componentes cognitivos e afetivos. Esses componentes apresentam dimensões como acessibilidade, confiabilidade, emoções e sentimentos, caracterizando a lealdade como construto multidimensional (Ellis, 2000; Dick e Basu, 1994).

A lealdade pode ser definida como o grau em que o cliente possui uma atitude positiva, apresenta comprometimento (vínculo emocional) e pretende continuar comprando no futuro (Mowen e Minor, 1998), ou seja, é a resposta comportamental resultante de um processo elaborado sobre uma ou mais opções alternativas. Essa situação implica compras repetidas baseadas em fatores cognitivos, afetivos, avaliativos e disposicionais, que são os componentes clássicos de uma atitude. A definição abaixo integra esses fatores no conceito de lealdade.

Lealdade é um comprometimento profundo em recomprar ou favorecer um produto/serviço no futuro, causando repetição de marca ou compra do mesmo conjunto de marcas, não obstante influências situacionais e esforços de marketing tenham potencial para causar um comportamento de troca (Oliver, 1999, p.34)

No que se refere ao processo de decisão do consumidor relacionado à intenção ou comportamento de recompra, pode-se afirmar que os componentes atitudinais e comportamentais nem sempre são considerados com a mesma intensidade. A combinação desses dois fatores leva a quatro situações diferentes, ilustradas na Figura 1.

\section{Figura 1: Tipos de Lealdade}

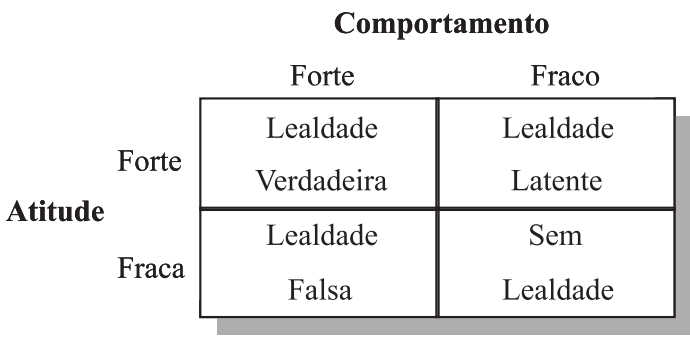

Fonte: adaptado de Dick, A. e Basu, K., 1994. 
Na lealdade verdadeira, a atitude é favorável e a recompra é consistente. Esta perspectiva considera, além do comportamento de recompra, os antecedentes de atitude que levam ao comprometimento do consumidor. Na lealdade falsa, também chamada de espúria, o cliente compra (forte comportamento), mas possui baixo comprometimento atitudinal (não possui preferência). Isto significa que outros fatores estão influenciando a compra deste cliente, como, por exemplo, preço mais baixo. Estas pessoas estão mais propensas a trocar de fornecedor em face de melhores alternativas. Portanto o índice de recompra nem sempre indica lealdade, porquanto a compra pode ter sido baseada em preço, conveniência, ou lealdade a mais de uma marca.

No nível de lealdade latente, apesar de possuir forte atitude, o cliente demonstra baixo nível de recompra, possivelmente devido a barreiras de acesso, como preço ou conveniência de compra. E, por fim, identifica-se o comportamento sem lealdade, que se refere a indivíduos que demonstram baixa atitude (não há preferência) e baixo comportamento (a compra não é regular).

O processo de formação da lealdade, segundo Oliver (1999), constitui-se de quatro fases, descritas na Figura 2. Conforme esse processo, percebe-se que a consistência do comportamento de lealdade se acentua, à medida que o consumidor avança em direção à fase ação. Na fase cognitiva, o consumidor processa informações a respeito do produto. As dimensões emocionais, sobretudo da satisfação, têm influência na formação da lealdade afetiva, derivada de atitude positiva. A partir dessas duas fases, origina-se a intenção de compra, caracterizando a lealdade conativa, isto é, o tipo de lealdade avaliado neste trabalho.

\section{Figura 2: Fases de Formação da Lealdade}

\begin{tabular}{|l|l|}
\hline Fase & \multicolumn{1}{|c|}{ Características } \\
\hline Cognitiva & $\begin{array}{l}\text { Lealdade à informação como preço, benefícios, qualidade } \\
\text { (características) etc. }\end{array}$ \\
\hline Afetiva & $\begin{array}{l}\text { Lealdade causada por afeto: "eu compro porque eu gosto". É sustentada } \\
\text { pela satisfação, envolvimento, preferência e consistência cognitiva. }\end{array}$ \\
\hline Conativa & $\begin{array}{l}\text { Lealdade como uma intenção: "eu estou comprometido a comprar". } \\
\text { Sustentada por comprometimento e consistência cognitiva. }\end{array}$ \\
\hline Ação & Lealdade como ação inercial. Sustentada pela inércia e custos perdidos. \\
\hline
\end{tabular}

Fonte: adaptada de Oliver (1997; 1999).

A lealdade conativa é estabelecida como intenção de recompra do consumidor por meio de um processo de aprendizagem. Basicamente duas teorias existentes na psicologia sustentam os principais modelos de aprendizagem: o modelo comportamental e o modelo cognitivo (Assael, 1992). 
O primeiro estuda apenas os aspectos comportamentais, por serem eles observáveis e mensuráveis. Essa teoria apregoa que o conhecimento dos processos mentais e fisiológicos que levam à ação não teriam influência relevante no estudo dos comportamentos. Portanto a aprendizagem consistiria apenas em se condicionar comportamentos. Existem dois tipos de condicionamento: o condicionamento clássico, associado a reflexos condicionados e a respostas naturais; e o condicionamento instrumental, que busca resposta ou reação nova por meio do aprendizado e é conseguido mediante reforços e repetições.

Desempenhando importante papel na formação da lealdade, a aprendizagem comportamental envolve a relação entre estímulo e resposta, onde o estímulo é o produto e a resposta é o comportamento de compra. No condicionamento instrumental, a conseqüência da ação influencia o comportamento futuro e, em tal contexto, sentimentos de recompensas e punições são fatores essenciais para prever o comportamento (Ellis, 2000). Por exemplo, se o consumidor está satisfeito com o produto ou compra, ele se sentirá recompensado e aumentará a probabilidade de que ele venha a repetir a compra. Se o consumidor está insatisfeito com o produto ou compra, ele se sentirá punido e a chance de recompra diminui. Assim, a satisfação ou insatisfação deriva de resultados agradáveis ou desagradáveis da experiência com o produto (o que é visto como recompensa ou punição); a lealdade é vista como busca de continuidade do ato recompensador, no caso de experiências positivas com o produto. Se a insatisfação ocorre, a probabilidade de compra subseqüente ao consumo diminui.

No que tange à aplicação do condicionamento instrumental em comportamento do consumidor, é importante entender que os consumidores geralmente recomprarão, quando a compra é reforçada. Então, a satisfação, se for considerada um reforço da avaliação pós-compra, pode ser fundamental para prever a lealdade, pois o consumidor satisfeito mantém o produto em mente e a probabilidade de ele vir a comprar este produto aumenta (Ellis, 2000).

O modelo cognitivo busca explicar fenômenos internos mais complexos, como a gênese da aprendizagem de conceitos e soluções de problemas. Considera aspectos inerentes ao indivíduo (como crenças e percepções) como determinantes do modo de apreensão da realidade (Assael, 1992). A aprendizagem cognitiva também apresenta influência na formação da lealdade. Atitudes são formadas a partir de "predisposições aprendidas a responder de uma maneira consistentemente favorável ou desfavorável a determinado objeto" (Fishbein e Ajzen, 1975). No desenvolvimento desse processo, são consideradas as crenças dos consumidores em relação às conseqüências da compra (Assael, 1992). Uma vez que o processamento de informação é inerente à concepção de atitude, pode-se dizer que a atividade cognitiva facilita a formação da lealdade. Conforme Ellis (2000), 
a lealdade pode ser formada a partir da satisfação, tanto pelo aprendizado comportamental como pelo cognitivo (atitudinal). Os resultados da autora revelam que a lealdade formada com base na atitude é mais forte do que a lealdade baseada no comportamento.

A teoria de aprendizagem fornece alguns indicadores de que a satisfação leva à lealdade, quando mostra que um cliente satisfeito se sente recompensado pelo consumo do produto e tende a buscar essa experiência novamente. No item seguinte, a relação entre satisfação e lealdade está abordada de maneira mais contígua, permitindo visualizar os principais achados teóricos relativos ao tema.

\section{A Satisfação como Antecedente da Lealdade}

Diversos estudos tratam a satisfação como importante fator para predizer as intenções de comportamento de recompra dos consumidores. Recentemente, Oliver (1999) analisou seis diferentes modelos, supondo relações possíveis entre os dois conceitos, afirmando que a satisfação é passo necessário na formação da lealdade, além de ser relativamente fácil de ser alcançada. $O$ autor concluiu que a melhor explicação para essa relação é uma transformação da satisfação em lealdade, "como uma lagarta se transforma em uma borboleta” (Oliver, 1999, p.42). Depois da transformação, os dois conceitos não se misturam e não têm características comuns, a não ser pelas suas origens. Embora o autor tenha salientado que a satisfação não é o único antecedente da lealdade, a sua conclusão fornece sustento para a relação proposta nesta investigação.

Na visão de alguns autores, quando os valores e expectativas do usuário são satisfeitos a partir da compra ou consumo do produto, o resultado é a lealdade (Sheth et al., 2001; Mowen e Minor, 1998). Resultados de testes empíricos sugerem forte relação entre as variáveis em estudo. Bolton (1998) comprovou que a satisfação com o serviço de uma empresa de telefonia móvel estava positivamente relacionada ao tempo que o indivíduo permanece como cliente da companhia. Outros estudos mostram que as intenções de recompra dependem das atitudes e do grau de satisfação anterior do consumidor (Bearden e Teel, 1983; Oliver, 1980; Boulding et al., 1993). Bitner (1990) afirma que a satisfação é um antecedente da lealdade, uma vez que uma das maneiras de ocorrência da resposta pós-compra do consumidor é por meio da confirmação de expectativas e qualidade percebida. Ao testar essa relação, Bolton e Drew (1991) encontraram correlação positiva entre os dois construtos.

Bloemer e Kasper (1994) realizaram um estudo que confirma que a satisfação manifesta (resultado de avaliação mais elaborada) tem mais influência na lealdade verdadeira do que a satisfação latente (a avaliação não é elaborada, não há comparação 
explícita das expectativas com o desempenho). De acordo com tais autores, a avaliação mais elaborada entre as expectativas e o desempenho, caso seja positiva, leva ao comprometimento, que é condição necessária da lealdade verdadeira.

De acordo com Mittal e Kamakura (2001), a relação existe, mas é assimétrica. Oliva, Oliver e MacMillan (1992) também sugerem que a relação entre satisfação (com um serviço) e lealdade não é linear. Uma relação assimétrica ocorre, quando a satisfação supera determinado limite superior ou inferior e, ao mesmo tempo, a lealdade também aumenta ou diminui consideravelmente; entre esses níveis críticos de satisfação, a lealdade permanece praticamente inalterada.

Apesar disso, e mesmo após a publicação de alguns trabalhos que buscaram outras variáveis para explicar a lealdade (Dick e Basu, 1994; Oliver, 1999), a satisfação continua sendo o seu principal prognóstico. A partir dessas evidências, sabe-se que a lealdade e a satisfação do consumidor estão conectadas inextricavelmente. Porém, conforme revela Oliver (1999), os aspectos da satisfação que têm implicações na lealdade e que porção da lealdade é determinada pelo componente satisfação ainda necessitam de aprofundamento teórico e evidências empíricas. Torna-se pertinente, então, uma tentativa de análise mais aprofundada da relação entre satisfação e lealdade, realizada com método mais rigoroso que tem como objetivo investigar essa relação em contexto específico.

Dessa forma, propõe-se o teste do modelo descrito na Figura 3, que pressupõe uma relação positiva entre os dois construtos em estudo. Salienta-se que este modelo, cuja principal relação é sustentada por pesquisas anteriores, conforme já mencionado, ilustra de forma simplificada uma situação da vida real. Deve-se considerar que todo o modelo é, de alguma forma, incompleto, pois versa apenas sobre parte do problema em tela. Entretanto esse é exatamente o objetivo e a principal vantagem da utilização de modelos teóricos: focar e analisar com precisão apenas parte do problema. Nesse caso, a satisfação foi medida no nível do atributo, enquanto a medida de lealdade envolveu duas variáveis utilizadas em pesquisas anteriores, conforme a descrição seguinte do modelo.

Figura 3: Modelo Proposto da Relação entre a Satisfação e a Lealdade do Consumidor

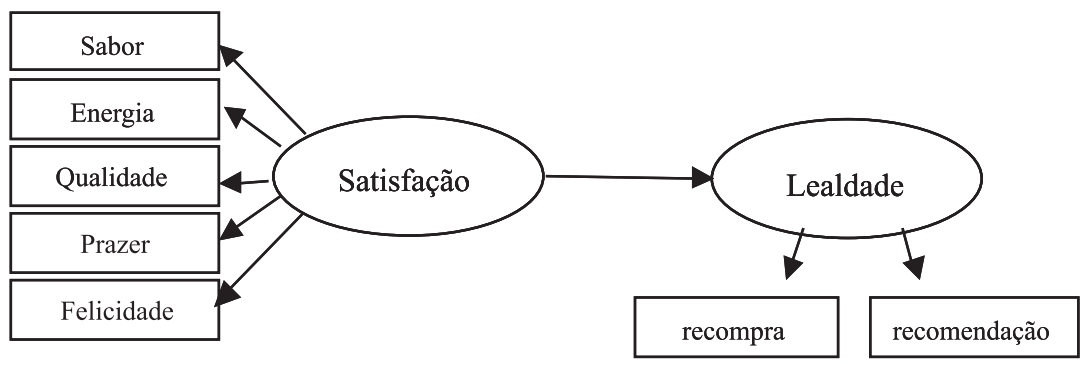




\section{MÉtodo}

Com o objetivo de testar empiricamente o modelo apresentado, o método de trabalho envolveu uma investigação caracterizada como experimento de campo (Churchill, 1999; Hair Jr. et al., 2000). Por serem realizados em ambiente próximo do ambiente de consumo natural, os experimentos de campo proporcionam ao estudo um nível mais elevado de realismo (Hair Jr. et al., 2000). Para avaliar a relação entre satisfação e lealdade, foi desenvolvido um modelo que pudesse avaliar a satisfação com os principais atributos do produto e, no que concerne à lealdade, pudesse abranger intenções de recompra e recomendação a terceiros.

\section{Amostra}

Os participantes foram selecionados por conveniência entre alunos de uma das maiores universidades brasileiras. A amostra é composta por pessoas com idade entre 18 e 50 anos, sendo 62\% composta por homens. Quase a metade (46\%) indicou ser consumidor de alimentos ecológicos, que representavam a categoria de produto em estudo. Ao final, os respondentes foram interrogados se sabiam o objetivo do experimento realizado, e nenhum indicou saber do que se tratava; caso contrário, isso poderia ter causado um viés nas respostas e alguns respondentes teriam de ser eliminados. O tamanho final da amostra, 204 casos, é suficiente para que sejam testados modelos estruturais de relacionamentos entre diversas variáveis (Hair, Jr. et al., 1998). A Tabela 1 sintetiza os dados sobre a amostra.

\section{Tabela 1: Caracterização da Amostra}

\begin{tabular}{ccc|c}
\hline & Características & Freqüência & \\
& & & \\
\hline Sexo & Masculino & 126 & 62,1 \\
& Feminino & 77 & 37,9 \\
\hline Idade & Até 20 anos & 42 & 20,8 \\
& De 21 a 25 anos & 34 & 16,8 \\
& De 26 a 30 anos & 32 & 15,8 \\
& De 31 a 35 anos & 28 & 13,9 \\
& Acima de 35 anos & 66 & 32,7 \\
\hline Renda Familiar & Até R\$ 1.000,00 & 2 & 1 \\
& Mais de R 1.000 a R $\$ 2.000$ & 25 & 12,3 \\
& Mais de R 2.000 a R 3.000 & 26 & 12,8 \\
& Mais de R\$ 3.000 a R $\$ 4.000$ & 23 & 11,3 \\
& Mais de R\$ 4.000 & 127 & 62,6 \\
\hline Consome alimentos & Sim & 92 & 46,5 \\
naturais & Não & 106 & 53,5 \\
\hline
\end{tabular}

Fonte: coleta de dados. 


\section{Procedimentos de Coleta de Dados}

Os respondentes foram selecionados em sala de aula e receberam um biscoito ecológico, sem agrotóxicos, para que fizessem a experimentação e avaliação de sua satisfação em relação ao produto. Seguindo a avaliação da satisfação, foram feitas perguntas relativas à probabilidade de recompra e recomendação a terceiros do produto.

Um produto ecológico foi selecionado devido à sua relação com questões ambientais e de saúde, o que tende a gerar maior envolvimento com o produto. Além disso, o aspecto e o sabor do biscoito não eram comparáveis aos biscoitos tradicionais vendidos no mercado, o que gerou sentimentos de satisfação e insatisfação entre os participantes, propiciando a variação necessária dos dados para que as relações entre as variáveis pudessem ser analisadas.

Apesar de os respondentes não terem comprado o biscoito de fato, os dados foram coletados em ambiente natural. A vantagem desse método, apontado na literatura como experimento de campo (Churchill, 1999), é que a avaliação da satisfação do consumidor é processada e mensurada logo após o consumo efetivo do produto, o que tende a propiciar um julgamento mais preciso e melhor mensuração das variáveis do modelo. Além disso, o controle de algumas variáveis foi benéfico aos objetivos da pesquisa. Por exemplo, foi utilizado um produto desconhecido, para que experiências anteriores com o produto não impactassem a satisfação e intenção de lealdade para com ele; a embalagem do produto não tinha nenhuma indicação de marca, para que questões anteriores de lealdade à determinada marca não influenciassem as respostas.

\section{Variáveis para a Mensuração dos Construtos}

O questionário foi elaborado a partir da literatura sobre alimentos e de entrevistas em profundidade realizadas com consumidores e não consumidores de alimentos naturais, peritos no assunto e estudantes universitários, que seriam o público de pesquisa. A partir dessa etapa, de caráter exploratório, foram selecionados catorze atributos relativos ao produto de análise da pesquisa, inseridos na primeira versão do questionário. Foi aplicado um pré-teste do questionário com 50 respondentes, com o objetivo de purificar as medidas. O pré-teste resultou na exclusão de quatro itens, que não eram claros para os respondentes ou tiveram respostas muito semelhantes (correlação acima de 0,90 ) a outros itens.

Esse procedimento resultou na escolha de 10 atributos de análise, de modo que os itens utilizados para medir satisfação foram os seguintes: o grau em que foi extremamente benéfico para minha saúde consumir esse alimento; o grau em 
que consumi um alimento de ótimo sabor; o grau em que o consumo desse alimento me fez sentir uma pessoa bastante preocupada com o meio-ambiente; o grau em que me senti com muito mais energia ao consumir esse alimento; o grau em que consumi um alimento de ótima qualidade; o grau em que foi extremamente prazeroso consumir esse alimento; o grau em que consumi um alimento muito mais completo em termos nutritivos; o grau em que me senti extremamente feliz ao consumir esse alimento; o grau em que consumi um alimento bastante crocante; o grau em que o consumo desse alimento poderá ajudar na melhora do meu metabolismo. Estes itens foram avaliados a partir de uma escala tipo Likert de sete pontos, variando de 1 (muito insatisfeito) a 7 (muito satisfeito).

Em relação às medidas de lealdade, foram empregadas duas variáveis utilizadas na literatura (Zeithaml et al., 1996; Sindershmukh et al., 2002) para medir esse construto, resultando nos seguintes itens de análise: eu recomendaria o consumo desse alimento para um amigo (relativo à variável de recomendação) e eu pretendo consumir esse alimento orgânico no futuro (relativo à variável de recompra). Esses itens também foram avaliados a partir de uma escala tipo Likert de sete posições, variando de 1 (discordo plenamente) a 7 (concordo plenamente).

\section{Processos Estatísticos de Análise}

Foi empregada a análise fatorial exploratória, com a utilização do software SPSS $10.0^{\oplus}$, e a modelagem de equações estruturais, realizada com o software AMOS $4^{\circledR}$.

O uso da modelagem de equações estruturais justifica-se no propósito do trabalho, que era lograr resultados rigorosos de avaliação das possíveis relações entre satisfação e lealdade. Essa técnica possibilita o uso de estrutura complexa de variáveis observadas (manifestas) e não-observáveis (latentes), bem como a análise de seus inter-relacionamentos (Hair, Jr. et al., 1998).

\section{Análise dos Dados e Resultados}

Primeiramente, foi realizada uma análise fatorial exploratória com o objetivo de purificar a medida de satisfação. Como o objetivo era reter um só fator que explicasse a maior parte possível da variância (acima de 50\%), cinco variáveis foram mantidas para a avaliação final: o grau em que consumi alimento de ótimo sabor; o grau em que me senti com muito mais energia ao consumir esse alimento; o grau em que consumi alimento de ótima qualidade; o grau em que foi 
extremamente prazeroso consumir esse alimento; o grau em que me senti extremamente feliz ao consumir esse alimento.

A partir daí foi realizada uma análise de valores omissos (missing values), que representam uma parcela praticamente nula das respostas, indicando boa compreensão dos itens questionados.

\section{Análises Descritivas}

As médias de cada variável utilizada para medir os construtos, em escalas de 1 a 7, bem como a fidedignidade das escalas, encontram-se na Tabela 2. Percebese que as médias de satisfação estão em patamares de médio para alto, acompanhadas das médias das variáveis de lealdade, que são altas. A medida de fidedignidade composta (Bagozzi, 1994) e o alpha de Cronbach indicam a adequação das escalas na medida das variáveis, pois estão acima dos valores mínimos exigidos.

\section{Tabela 2: Médias das Variáveis}

\begin{tabular}{|c|c|c|c|c|c|}
\hline Construto & $\begin{array}{l}\text { Fidedignidade } \\
\text { Composta }\end{array}$ & $\begin{array}{l}\text { Alpha de } \\
\text { Cronbach }\end{array}$ & Variável & Média & $\begin{array}{l}\text { Desvio- } \\
\text { Padrão }\end{array}$ \\
\hline \multirow{5}{*}{ Satisfação } & \multirow{5}{*}{0,60} & \multirow{5}{*}{0,89} & Sabor & 3,63 & 1,81 \\
\hline & & & Energia & 3,48 & 1,45 \\
\hline & & & Qualidade & 4,50 & 1,60 \\
\hline & & & Prazer & 3,45 & 1,73 \\
\hline & & & Felicidade & 3,33 & 1,53 \\
\hline \multirow[t]{2}{*}{ Lealdade } & \multirow[t]{2}{*}{0,92} & \multirow[t]{2}{*}{0,86} & $\begin{array}{c}\text { Recomendação a } \\
\text { Terceiros }\end{array}$ & 4,84 & 1,82 \\
\hline & & & Intenção de Recompra & 5,16 & 1,76 \\
\hline
\end{tabular}

Fonte: coleta de dados.

\section{Modelagem de Equações Estruturais}

Após a purificação das medidas de satisfação por meio de análise fatorial exploratória, com retenção das medidas que explicavam a maior parte da variância da satisfação, foi avaliado o modelo final de relação entre a satisfação e a lealdade, conforme ilustra a Figura 3. Esse método foi utilizado, pois o principal objetivo da modelagem de equações estruturais, segundo Kline (1998), é explicar o padrão de uma série de relações de dependência, inter-relacionadas simultaneamente, entre construtos latentes (como a satisfação e a lealdade), medidos por variáveis observáveis (como os atributos do produto e as intenções de recompra e recomendação a terceiros). 
Os índices de ajustamento, que indicam a adequação do modelo, foram aceitáveis, com $\chi^{2}=81,36 ; \mathrm{GL}=13$; $\mathrm{p}<0,001$; GFI = 0,90; AGFI = 0,79; IFI = 0,93; TLI =0,88; CFI =0,93; RMSEA =0,16. Torna-se difícil avaliar o ajuste do modelo como um todo, pois a estatística qui-quadrado foi significante e o índice RMSEA ficou acima do patamar máximo desejável de 0,08. No entanto, ao considerar índices como o GFI, o IFI, o CFI e o TLI, pode-se afirmar que o modelo apresenta um ajuste razoável, refletindo cada construto adequadamente.

Além disso, todas as cargas fatoriais das variáveis observáveis foram significativas em seus construtos $(\mathrm{p}<0,05)$ e as variáveis de um mesmo construto apresentaram alta correlação, o que indica uma relação linear significante entre as variáveis observáveis e suas respectivas variáveis latentes. Essas relações são apresentadas na Tabela 3.

\section{Tabela 3: Variáveis Latentes e Observáveis}

\begin{tabular}{c|c|c|c|c}
\hline Construto & Variável Observável & $\begin{array}{c}\text { Parâmetro } \\
\text { Padronizado }\end{array}$ & Significância & $\begin{array}{c}\text { Correlação } \\
\text { Múltipla ao } \\
\text { Quadrado }\end{array}$ \\
\hline \multirow{4}{*}{ Satisfação } & Sabor & $\mathbf{0 , 8 8}$ & $\mathbf{p}<\mathbf{0 , 0 0 1}$ & $\mathbf{0 , 7 8}$ \\
\cline { 2 - 5 } & Energia & $\mathbf{0 , 5 9}$ & $\mathbf{p}<\mathbf{0 , 0 0 1}$ & $\mathbf{0 , 3 5}$ \\
\cline { 2 - 5 } & Qualidade & $\mathbf{0 , 6 5}$ & $\mathbf{p}<\mathbf{0 , 0 0 1}$ & $\mathbf{0 , 4 2}$ \\
\cline { 2 - 5 } & Prazer & $\mathbf{0 , 9 3}$ & $\mathbf{p}<\mathbf{0 , 0 0 1}$ & $\mathbf{0 , 8 6}$ \\
\hline \multirow{2}{*}{ Lealdade } & Felicidade & $\mathbf{0 , 8 4}$ & $\mathbf{p}<\mathbf{0 , 0 0 1}$ & $\mathbf{0 , 7 1}$ \\
& $\begin{array}{c}\text { Recomendação a } \\
\text { Terceiros }\end{array}$ & $\mathbf{0 , 9 7}$ & $\mathbf{p}<\mathbf{0 , 0 0 1}$ & $\mathbf{0 , 9 4}$ \\
\cline { 2 - 5 } & Intenção de Recompra & $\mathbf{0 , 7 8}$ & $\mathbf{p}<\mathbf{0 , 0 0 1}$ & $\mathbf{0 , 6 1}$ \\
\hline
\end{tabular}

Fonte: coleta de dados.

No que se refere à investigação principal da pesquisa, a relação entre satisfação e lealdade, observou-se uma carga de 0,66 entre essas variáveis, com um valor da estatística t de 7,54, que representa relação significativa no nível $\mathrm{p}<0,001$. A correlação múltipla ao quadrado entre essas variáveis é de 0,44 , ou seja, a variável satisfação explica 44\% da lealdade. Esses números são sintetizados na Tabela 4.

\section{Tabela 4: Relação entre as Variáveis Lealdade e Satisfação}

\begin{tabular}{c|c|c|c|c}
\hline $\begin{array}{c}\text { Variável de } \\
\text { Causa }\end{array}$ & \multicolumn{4}{|c}{$\begin{array}{c}\text { Variável de Efeito } \\
\text { Lealdade }\end{array}$} \\
\hline \multirow{2}{*}{ Satisfação } & Carga do Parâmetro & Estatística t & Significância & $\begin{array}{c}\text { Correlação } \\
\text { Múltipla ao } \\
\text { Quadrado }\end{array}$ \\
\cline { 2 - 5 } & 0,66 & 7,54 & $\mathbf{p}<0,001$ & 0,44 \\
\hline
\end{tabular}

Fonte: coleta de dados. 
A partir desses números pode-se estabelecer forte relação entre as variáveis, pois a carga do parâmetro foi elevada, dentro de um modelo razoavelmente ajustado, bem como a correlação múltipla foi alta, indicando que a satisfação sozinha explica boa parte da lealdade. A partir dos resultados obtidos, são discutidas agora as principais implicações gerenciais da pesquisa realizada, bem como suas limitações e sugestões para pesquisas futuras.

\section{Dıscussão}

Os resultados da pesquisa confirmaram a relação positiva entre satisfação e lealdade do consumidor, indicando que clientes satisfeitos tendem a ser mais leais. Mesmo que avaliações subjetivas já fossem nessa direção, é ressaltada a carência de comprovações empíricas como aquelas apresentadas aqui. Além disso, uma medida mais precisa da parte da variância da lealdade que é explicada pela satisfação vem a confirmar as contribuições do estudo.

O método de investigação, em que o consumo do produto e a avaliação foram feitos em curto espaço de tempo, propiciou uma medida mais pura das variáveis de satisfação e lealdade, sem a influência de outras variáveis, como comunicações interpessoais, tempo de uso do produto ou preço. Com isso avaliou-se parte do processo psicológico que transforma satisfação em lealdade, a partir de dados com menos ruídos e condizentes aos objetivos da pesquisa.

Integrando as evidências teóricas existentes ao resultado obtido, a pesquisa proporciona o aprofundamento do estudo dos desdobramentos da satisfação. Isso abre uma oportunidade para um entendimento mais detalhado, acompanhado de base empírica, do processo de resposta do consumidor às experiências de consumo. O tema merece atenção, uma vez que possui amplo espaço para ser desenvolvido academicamente e tem alto valor gerencial, dada a importância de respostas, como a lealdade e a comunicação boca-a-boca, por exemplo.

Por outro lado, sendo a satisfação um dos antecedentes afetivos da lealdade, ao lado de emoções, humor e afeto (Dick e Basu, 1994), a relação aqui proposta e avaliada contribui para a compreensão desses fatores afetivos no estudo da lealdade e, igualmente, na pesquisa do consumidor. Além disso, os resultados encontrados (44\% da variância da lealdade explicada pela satisfação) indicam que este componente pode ser o principal determinante do comportamento de recompra do consumidor.

Embora os resultados encontrados possam sugerir tal inferência, deve-se 
lembrar, todavia, que outros antecedentes da lealdade também podem explicar a dita variável. De forma semelhante, as conseqüências da satisfação dos consumidores desbobram-se em outros fatores, além da lealdade, como, por exemplo, a propaganda boca-a-boca. Conforme foi destacado anteriormente, o objetivo deste artigo foi analisar essa relação específica e trazer evidências empíricas para a possível expansão do modelo, de forma que ele consiga capturar parcela maior da realidade. Adicionalmente, a procura por melhores explicações do comportamento de lealdade requer que os outros determinantes da lealdade sejam identificados, conforme atesta Oliver (1999).

Em termos gerenciais, pode-se afirmar que a empresa empreendedora de uma estratégia de retenção de clientes deve, primeiramente, entender os requisitos básicos para a manutenção de clientes satisfeitos. Sendo a lealdade um estado de preferência que parte do cliente, a empresa tem de oferecer aqueles fatores que o satisfazem, para que, a partir de um processo cognitivo-afetivo de formação do comprometimento, a lealdade seja estabelecida. Além disso, certa mudança na ênfase da satisfação para a lealdade parece ser valiosa, já que o impacto da lealdade dos clientes, na lucratividade das empresas, é entendido como positivo (Oliver, 1999; Reichheld, 1996).

A relação positiva entre satisfação e lealdade traz implicações importantes para o marketing de relacionamento, que busca a retenção por meio do estabelecimento de transações relacionais com os clientes. Para que essa estratégia seja bem sucedida, é preciso investir nos clientes certos. As relações de troca relacionais, assim como a lealdade, têm componente afetivo muito forte: o comprometimento. Os clientes verdadeiramente leais são fiéis à empresa e, por isso, tendem a inserir-se em relações de troca relacionais e não apenas transacionais. Dessa maneira, por meio do estabelecimento da lealdade e/ou da identificação de clientes fiéis, a empresa possuirá um conjunto de clientes com alto potencial para o relacionamento.

\section{Limitações e Sugestões de Pesquisas Futuras}

O estudo considerou apenas um determinante da lealdade, a satisfação, que explicou grande parte da lealdade dos consumidores entrevistados. A situação desenvolvida no experimento de campo para analisar a relação proposta não considera o fato de que a lealdade, em situações reais de mercado, pode ser gerada, quando os consumidores não têm outra alternativa de produto ou serviço. Visto que neste trabalho se objetivou avaliar a predisposição à lealdade, essa variável não foi incluída no estudo, o que abre espaço para apreciação mais aprofundada em pesquisas futuras. 
Sugere-se que outros estudos, envolvendo os antecedentes da lealdade, sejam realizados, para determinar outros fatores importantes no entendimento dessa variável. Alguns fatores adicionais, que podem ser motivos pelos quais os consumidores se tornam leais, são o conforto de não ser forçado a tomar uma decisão, a redução do tempo e esforço despendidos no processo de compra, a familiaridade com a marca ou a redução do risco percebido (Bloemer e Kasper, 1995). Além de outros antecedentes, podem ser avaliadas variáveis moderadoras como a confiança, o comprometimento (Hennig-Thurau e Klee, 1997) e o envolvimento (Bloemer e Kasper, 1995).

Espera-se que os resultados encontrados sirvam de motivação para o desenvolvimento de trabalhos que aprimorem o método utilizado e avaliem pontos pouco explorados, proporcionando evolução importante para acadêmicos e praticantes de marketing.

\section{Artigo recebido em 14.11.2002. Aprovado em 24.11.2003.}

\section{REFERÊNCIAS}

ANDERSON, E. W.;

FORNELL, C.;

LEHMANN, D. R.,

Customer satisfaction, market share, and profitability: findings from Sweden. Journal of Marketing, vol.58, n.3, p. 53-66, 1994.

ASSAEL, $\mathrm{H}$.

Consumer behavior and marketing action. 4. ed. Boston: Kent Pub. Co., 1992

\section{BAGOZZI, R. P.}

Structural equations models in marketing research: basic principles. In Principles of Marketing Research. Cambridge: Blackwell, p. 317-385, 1994.
BEARDEN, W. O.;

TEEL, J.E.

Selected determinants of consumer satisfaction and complaint reports. Journal of Marketing Research, vol.20, n.1, p. 21-28, 1983.

BITNER, M. J.

Evaluating service encounters: the effects of physical surroundings and employee responses. Journal of Marketing, vol. 54, n. 2, p. 69-82, 1990.

BLOEMER, J. M. M.;

KASPER, H. D. P.

The impact of satisfaction on brand loyalty: urging on classifying satisfaction and brand loyalty. Journal of Consumer Satisfaction, Dissatisfaction and Complaining Behavior, vol.7, p.152-160, 1994. 
The complex relationship between consumer satisfaction and brand loyalty. Journal of Economic Psychology, vol.16, n.2, p. 311-329, 1995.

\section{BOLTON, R. N.}

A dynamic model of the duration of the customer's service provider: the role of satisfaction. Marketing Science, vol. 17, n.1, 1998.

BOLTON, R. N.;

DREW, J. H.

A multistage model of customer's assessment of service quality and value. Journal of Consumer Research, vol.17, n.4, p.375-384, 1991

\section{BOULDING, W.;}

STAELIN, R.;

KALRA, A.;

ZEITHAML, V.

A Dynamic Process Model of Service Quality: From Expectations to Behavioral Intentions. Journal of Marketing Research, vol.30, n.1, p.727, feb. 1993.

\section{CHURCHILL, Jr., G. A.}

Marketing research: methodological foundations. 7.ed. Orlando: Dryden Press, 1999.

CHURCHILL, Jr. G.;

\section{SURPRENANT, C.}

An investigation into the determinants of customer satisfaction. Journal of Marketing Research, vol.19, n.4, p. 491-504, 1982.
CRONIN, J.;

TAYLOR, S. A.

Measuring service quality: a reexamination and extension, Journal of Marketing, vol.56, n.3, p. 55-68, jul. 1992.

DICK, A.;

BASU, K.

Customer loyalty: toward an integrated conceptual framework. Journal of the Academy of Marketing Science, vol.22, n.2, p. 99-114, 1994.

ELLIS, T. B.

The development, psychometric evaluation and validation of a customer loyalty scale. Cardondale, 2000. Doctoral Dissertation (Doctor of Philosophy in Psychology), Department of Psychology in the Graduate School Southern Illinois University.

EVRARD, Y.

La satisfaction des consommateurs: état des recherches. Revue Française du Marketing, n. 144-145, p. 53-65, 1993.

FISHBEIN, M.;

AJZEN, I.

Belief, attitude, intention and behavior: an introduction to theory and research. Menlo Park, CA: Addison-Wesley Publishing Co., 1975.

FORNELL, C.

A National customer satisfaction barometer: the Swedish experience, Journal of Marketing, vol.56, n.1, p.6-21, 1992. 
GARBARINO, E.;

JOHNSON, $\mathrm{M}$.

The different roles of satisfaction, trust, and commitment in customer relationships. Journal of Marketing, vol. 63, n.2, p. 70-87, 1999.

HAIR, Jr., J. F.;

ANDERSON, R. E.;

TATHAM, R. L.;

BLACK, W. C.

Multivariate data analysis. 5.ed. New Jersey: Prentice Hall, 1998.

HAIR, Jr., J. F.;

BUSH, Robert P.;

ORTINAU, D. J.

Marketing research: a practical approach for the new millennium. Boston: Irwin McGraw-Hill, 2000.

HENNIG-THURAU, T.;

KLEE,A.

The impact of customer satisfaction and relationship quality on customer retention: a critical reassessment and model development. Psychology \& Marketing, vol. 14, n.8, p. 737-764, 1997.

JAP, S. D.

The strategic role of the salesforce in developing customer satisfaction across the relationship lifecycle. The Journal of Personal Selling \& Sales Management. vol.21, n.2, p.95-108, 2001.

KLINE, R. B.

Principles and practice of structural equation modeling. New York: The Guilford Press, 1998.
LEMON, K. N;

WHITE, T. B.;

WINER, R.

Dynamic customer relationship management: incorporating future considerations into the service retention decision. Journal of Marketing, vol. 66, n.1, p.1-14, 2002.

MITTAL, V.;

KAMAKURA, W.A.

Satisfaction, repurchase intent and repurchase behavior: investigating the moderating effect of customer characteristics. Journal of Marketing Research, vol.28, n.1, p.131-142, 2001.

MOWEN, J. C.;

MINOR, $\mathrm{M}$.

Consumer behavior. 5. ed. Upper Saddle River: Prentice-Hall, 1998.

OLIVA, T.A.;

OLIVER, R. L.;

MACMILLAN, I. C.

A catastrophe model for developing service satisfaction strategies. Journal of Marketing, vol.56, n.3, p.83-96, 1992

OLIVER, R. L.

A cognitive model of the antecedents and consequences of satisfaction decisions. Journal of Marketing Research, vol.17, p. 460-469, 1980.

Satisfaction: a behavioral perspective on the consumer. New York: McGraw Hill, 1997.

Whence consumer loyalty? Journal of Marketing, vol.63 (special issue), p. 33-44, 1999. 
REICHHELD, F.

The loyalty effect: the hidden force behind growth, profits, and lasting value. Boston: Harvard Business Review Press, 1996.

SHETH, J.;

MITTAL, B.;

NEWMAN, B.

Comportamento do cliente: indo além do comportamento do consumidor. São Paulo: Atlas, 2001.

SIRDESHMUKH, D.;

SINGH, J.;

SABOL, B.

Consumer trust, value and loyalty in relational exchanges. Journal of Marketing, vol. 66, n.1, p. 15-37, 2002.
SOLOMON, M. R.

Consumer Behavior: buying, having and being. 3.ed. Upper Saddle River: Prentice Hall, 1999.

ZEITHAML, V.;

BERRY,L.;

PARASURAMAN, A.

The behavioral consequences of service quality. Journal of Marketing, vol. 60, n.2, p. 31-46, 1996. 